\title{
Cardiovascular Diseases among Suiciders: A Population-Based Study in Northern Finland Population
}

\author{
Arja Mainio, ${ }^{1,2}$ Helinä Hakko, ${ }^{1,2}$ Pirkko Räsänen, ${ }^{1,2}$ and Markku Timonen ${ }^{1,2}$ \\ ${ }^{1}$ Department of Psychiatry, University of Oulu, P.O. Box 5000, 90014 Oulu, Finland \\ ${ }^{2}$ Department of Psychiatry, Oulu University Hospital, P.O. Box 26, 90029 OYS, Finland \\ Correspondence should be addressed to Arja Mainio, arja.mainio@oulu.fi
}

Received 18 March 2010; Revised 23 May 2010; Accepted 18 June 2010

Academic Editor: Kate Scott

Copyright ( 2010 Arja Mainio et al. This is an open access article distributed under the Creative Commons Attribution License, which permits unrestricted use, distribution, and reproduction in any medium, provided the original work is properly cited.

\begin{abstract}
Objective. Depression has been found to be an independent risk factor with cardiovascular diseases (CVDs) and also associated with increased mortality among these patients. Method. We used a comprehensive database of all suicides $(n=2,283)$ committed in Northern Finland with information on all hospital-treated cardiovascular diseases and psychiatric disorders. Results. Coronary artery disease (CAD) had been present in $7.7 \%$ and other cardiovascular diseases (CVDs) in 11.6\% of the suiciders. The likelihood of suicide for patients with hospital-treated CAD was estimated to be two-fold compared to the general population while likelihood for suicide was not elevated among those with other CVDs. Males with CAD and females with CAD or any CVD had been hospitalized significantly more often with depression compared to reference group. Conclusions. Suicidality among patients with cardiovascular diseases has been suggested to associate with depression. Psychiatric consultation is highly recommended in clinical practice for cardiac patients with depression or alcohol-related disorders.
\end{abstract}

\section{Introduction}

Depression has shown to be an independent risk factor for the onset of various cardiovascular diseases (CVDs) [1-4], such as myocardial infarction, coronary artery disease and cerebrovascular diseases, reviewed by Van der Kooy, and his coworkers [3]. The background behind this association has not been fully solved, and it has been suggested that depression causes heart disease either through behavioral factors, autonomic dysfunction, or inflammatory intermediates [5]. Furthermore, both major depression and depressive symptoms after myocardial infarction are linked with increased mortality as an independent risk factor among cardiac patients $[6,7]$.

Although depression and CVD are found to be highly and reciprocally associated with each other, there are only a few studies on suicidality among cardiac patients $[8,9]$. Given the high prevalence (12-20\%) of depression in hospitalized cardiac patients [10] and the possibility that depression is a more important predictor of suicide in the hospital than in the community, diagnosing depression in hospital settings may be a major factor in suicide prevention [11].

In order to study suicides among cardiac patients we had an access to a large Finnish suicide database. The aims of the present study were, firstly, to study the prevalence of cardiovascular diseases (CVDs) in the suicide population, and secondly, to evaluate separately the specific features of suicide completers according to CVD; that is, either coronary artery disease (CAD) or other CVDs. Further, we also calculated an estimate for the probability of suicide for patients with hospital-treated CAD as well as other CVDs in the general population.

\section{Methods}

We examined all suicides $(n=2,283)$ committed during the years 1988-2007 in the province of Oulu in Northern Finland. The data on age, gender, suicide methods, previous suicide attempts, and abuse of alcohol at the time of the suicide were based on death certificates from forensic 
TABLE 1: The characteristics of the suicide victims according to cardiovascular disease.

\begin{tabular}{lccc}
\hline & $\begin{array}{c}\text { Coronary artery disease } \\
n(\%)=176\end{array}$ & $\begin{array}{c}\text { Other cardiac disease } \\
n(\%)=266\end{array}$ & $\begin{array}{c}\text { No cardiac disease } \\
n(\%)=1841\end{array}$ \\
\hline Males & $156(88.6)$ & $191(71.8)$ & $1516(82.3)$ \\
\hline $\begin{array}{l}\text { Mean (std) age in years } \\
\text { at the time of death }\end{array}$ & $62.1(12.9)$ & $52.7(14.3)$ & $40.3(14.4)$ \\
\hline $\begin{array}{l}\text { Violent method for } \\
\text { suicide }\end{array}$ & $129(73.3)$ & $183(68.8)$ & $1393(75.7)$ \\
\hline $\begin{array}{l}\text { Hanging } \\
\text { Shooting }\end{array}$ & $64(36.4)$ & $92(34.6)$ & $512(27.8)$ \\
Poisoning & $38(21.6)$ & $54(20.3)$ & $569(30.9)$ \\
Gas & $37(21.0)$ & $73(27.4)$ & $322(17.5)$ \\
Traffic & $10(5.7)$ & $10(3.8)$ & $126(6.8)$ \\
Jumping & $4(2.3)$ & $2(0.8)$ & $87(4.7)$ \\
Drowning & $5(2.8)$ & $5(1.9)$ & $44(2.4)$ \\
Other & $14(8.0)$ & $23(8.6)$ & $125(6.8)$ \\
\hline Previous suicide attempt & $4(2.3)$ & $7(2.6)$ & $56(3.0)$ \\
\hline Alcohol contributed to & $14(8)$ & $92(34.6)$ & $193(10.5)$ \\
the suicide & $62(35.2)$ & $849(46.1)$ & .050 \\
\hline
\end{tabular}

* Pearson $\chi^{2}$-test or Fisher Exact test when appropriate, two-tailed significance.

$* *$ Kruskall-Wallis test, two-tailed significance.

medical-legal investigations. The Ethics Committee of Oulu University has approved the study protocol. The diagnoses of subjects were extracted from the Finnish Hospital Discharge Registers (FHDR). The FHDR covers all treatment episodes in general, mental, military, prison, and private hospitals, as well as the inpatient wards of local health centers nation-wide. The FHDR contains the personal and hospital identification codes, data on age, gender, length of stay, and primary diagnosis at discharge, together with three subsidiary diagnoses. The International Classification of Diseases (ICDs) was used as follows: CVD were classified as (1) Coronary artery disease (CAD) ICD8: 410-414.99 and 440-441.99; ICD9: 410-4149X and 440-4409X; ICD10: I20-I25 and I70-I70.9 and (2) Other cardiovascular diseases ICD8: 390-398.99, 400-404.99, 420-429.99 and 441-448.09; ICD9: 390-3989X. 401-4059X, 420-4299X and 441-4489X; ICD10: I00-I02, I05-I15, I30-I52, I71-I74, I77-I79.8.

Psychiatric disorders were categorized as follows: (1) Depression ICD-8: 2960, 2980, 3004; ICD-9: 2961, 2968, 3004; ICD-10: F32-F34.1. (2) Psychotic disorders ICD-8: 296-299; ICD-9: 2961-4E, 2967A, 297, 298, 2990, 2999; ICD10: F22-25, F28, F29, F30.2, F31.2, F31.5, F32.3, F33.3, (3) Substance use disorders ICD-8 303-304; ICD-9 303-305; ICD-10:F10-19. (4) Other psychiatric disorders; all other diagnoses apart early mentioned. We used in the present study primary diagnosis as well as subsidiary diagnoses.

The prevalence of suicides, CVDs, and population figures for those aged 15 years or older were obtained from Statistics Finland and the database from the National Institute of Health and Welfare.

The methods for suicide among study subjects were categorized as violent if the method was hanging, drowning, shooting, wrist cutting, jumping from a height, or traffic. Nonviolent methods were poisoning, gas, or other methods.
Acute alcohol intoxication was detected in the medical autopsy by a doctor in forensic medicine and entered on the death certificate.

\section{Statistical Analyses}

Statistical significance of group differences in categorical variables was examined with Pearson $\chi^{2}$-test or Fisher Exact test. Statistical significance of group differences in continuous variables was analyzed with the Mann-Whitney U-test or Kruskall-Walls test. The statistical significance of differences between repeated measurements were assessed with Wilcoxon signed rank test (two repeated measurements). By using the prevalence of suicide and CVDs in the general Finnish population and prevalence of CVDs in our database Bayes Rule for conditional probabilities was used to calculate the probability of suicide given that the person had any CVD. All statistical analyses were performed by using the SPSS statistical software, version 17, and the results in this study were considered statistically significant when the appropriately calculated two-tailed $P$-value was $\leq .05$.

\section{Results}

Of the total suicide data population $(n=2,283), 19.3 \%$ ( $n=$ 442) had hospital-treated any CVD during their lifetime. CAD had been diagnosed in 7.7\% (176) and other CVD in $11.6 \%(266)$ of the suiciders. Table 1 shows the clinical and suicide characteristics of the suiciders with or without CVD. Compared to other suiciders, those with other CVD than CAD had used significantly more often a nonviolent method, $P=.050$ Pearson $\chi^{2}$-test. The most commonly used suicide method among suiciders with CAD (36.4\%) 
TABLe 2: Prevalence of psychiatric disorders among suiciders in males and females.

\begin{tabular}{|c|c|c|c|c|c|c|c|c|}
\hline \multirow[b]{2}{*}{$\begin{array}{l}\text { Psychiatric } \\
\text { disorder }\end{array}$} & \multicolumn{4}{|c|}{ Males } & \multicolumn{4}{|c|}{ Females } \\
\hline & $\begin{array}{l}\text { Coronary } \\
\text { artery disease } \\
n(\%)=156\end{array}$ & $\begin{array}{l}\text { Other cardiac } \\
\text { disease } \\
n(\%)=191\end{array}$ & $\begin{array}{l}\text { No cardiac } \\
\text { disease } \\
n(\%)=1516\end{array}$ & $P$ value* & $\begin{array}{l}\text { Coronary } \\
\text { artery disease } \\
n(\%)=20\end{array}$ & $\begin{array}{l}\text { Other cardiac } \\
\text { disease } \\
n(\%)=75\end{array}$ & $\begin{array}{l}\text { No cardiac } \\
\text { disease } \\
n(\%)=325\end{array}$ & $P$ value ${ }^{*}$ \\
\hline Depression & $43(27.6)$ & $29(15.2)$ & $164(10.8)$ & $\begin{array}{l}<.001 \\
.005^{* *}\end{array}$ & $7(35.0)$ & $35(46.7)$ & $82(25.2)$ & .001 \\
\hline $\begin{array}{l}\text { Alcohol- } \\
\text { related } \\
\text { disorders }\end{array}$ & $34(21.8)$ & $47(24.6)$ & $208(13.7)$ & $<.001$ & $2(10.0)$ & $4(5.3)$ & $26(8.0)$ & .676 \\
\hline
\end{tabular}

* Fischer exact test, two-tailed significance.

** Coronary artery disease versus other cardiovascular disease.

and CVD (34.6\%) was hanging, followed by shooting and poisoning among CAD sufferers, while those with other CVD than CAD had used poisoning. The majority of the suiciders with CVD $(65 \%)$ were not under the influence of alcohol at the time of suicide.

Table 2 shows hospital-treated psychiatric disorders according to gender. The suiciders with CVDs had significantly more often hospital-treated psychiatric disorders in their life-time history compared to those with no CVD. Both the male and female suiciders with CAD had significantly more often been treated in hospital due to their depression compared those with no CVD. Females with other CVDs had hospitalized significantly more often due their depression than those without any CVD. The male suiciders with any CVD had significantly more often alcohol-related disorders compared to those without any CVD.

The Bayes Rule for conditional probabilities was used to estimate the probability of suicide among hospital-treated patients with CVDs. The prevalence of suicide in Finnish general population is $0.03 \%$. The prevalence of hospitaltreated CADs, as well other CVDs in the general Finnish population (aged 15 years or over) are $3.7 \%$, and $10.8 \%$, respectively, (Table 3 ). In our study, the prevalence of CAD among suicide suiciders was $7.7 \%$ and other CVDs $11.6 \%$, respectively. The probability of suicide among patients with CAD was $0.06 \%$ and among suiciders with other CVDs was $0.03 \%$. Thus, the likelihood of suicide was two-fold for patients with hospital-treated CADs compared to the general population, while likelihood for suicide was among those with other CVDs was the same as likelihood for suicide in the general population.

\section{Discussion}

We found that about one in five of all the subjects in this large population-based suicide data set from Northern Finland had suffered from any cardiovascular disease. To our knowledge, this is the first time that life-time prevalence of CVDs was investigated among suiciders. Earlier studies have pointed out an increase in suicide attempts among CAD patients [8]. In the present study, about $8 \%$ of the suiciders had $\mathrm{CAD}$ and $12 \%$ from other CVDs than CAD. The prevalence of hospital-treated CVDs among suiciders was
Table 3

(a) Numbers of patients with hospital-treated cardiovascular diseases in general population according to Finnish Hospital Discharge Registers (FHDR).

\begin{tabular}{lllll}
\hline & $\begin{array}{l}\text { Coronary } \\
\text { artery disease }\end{array}$ & $\begin{array}{l}\text { Other } \\
\text { cardiovascular } \\
\text { disease }\end{array}$ & $\begin{array}{l}\text { No } \\
\text { cardiovascular } \\
\text { disease }\end{array}$ & Total \\
\hline Patients & $\begin{array}{l}30579 \\
(3.7 \%)\end{array}$ & $\begin{array}{l}90255 \\
(10.8 \%)\end{array}$ & $\begin{array}{l}717578 \\
(85.5 \%)\end{array}$ & 838412 \\
Males & $56 \%$ & $48 \%$ & $43 \%$ & \\
$\begin{array}{l}\text { Mean age } \\
\text { in yrs }\end{array}$ & 75 & 70 & 64 & \\
\hline
\end{tabular}

(b) Number of hospital-treated patients according to psychiatric disorders.

\begin{tabular}{lcll}
\hline & Depression & $\begin{array}{l}\text { Alcohol related } \\
\text { disorders }\end{array}$ & $\begin{array}{l}\text { Any psychiatric } \\
\text { disorder }\end{array}$ \\
\hline Patients & 9951 & $\begin{array}{l}15738 \\
(24 \%)\end{array}$ & 64238 \\
Males & $38 \%$ & $78 \%$ & $51 \%$ \\
Age in yrs & 54 & 48 & 50 \\
\hline
\end{tabular}

not elevated being about the same as in general population in Finland which is shown to be $11 \%$. However, the prevalence of hospital-treated CAD among suiciders was twice as high as in general population [12]. In terms of the probability of suicide among patients with hospital-treated CAD, these patients were estimated to have a two-fold risk for suicide than in the general population. Our finding is in line with the Brazil mortality study which recently found that the incidence of deaths from suicide was positively correlated with deaths from ischemic heart disease but not from other cardiovascular diseases [11]. Also, it has previously been shown that the percentage of suicides in persons with cerebrovascular disease, that is, among stroke patients was as high as $7.2 \%$ in the Danish population [13]. Further studies would be needed to extract more information on special risk factors for suicide risk among CAD patients.

Cardiovascular diseases, especially CAD, are often associated with depression [1-3]. In our study, both the male 
and female suiciders with CAD had been diagnosed with depression more often than the reference ones. The prevalence of hospital treated depression in Finnish population according to Finnish Hospital Discharge Registers (FHDR) [12] has shown to be about the same as in the suiciders with CVDs in the present study. However, the prevalence of depression among suiciders with CAD was twice as the corresponding prevalence in Finnish hospital patients. We suggest that depression among CAD patients is a remarkable contributor for suicide.

The prevalence of substance-related diseases was also higher in the males with any cardiovascular disease but this prevalence was not higher than among the patients with Finnish general hospital treated patients. Also, alcohol was significantly less often contributed to suicide among those with any cardiovascular diseases compared to those without CVDs. In our opinion, at least two issues in the background of this result can be noticed. Firstly, we suggest that suicide is mainly committed without alcohol intake and is thus nonimpulsive and premeditated before the definitive accomplishment of suicide. Secondly, the lower alcohol influence can be associated with significantly older age among CVD suiciders.

According to our study, the profile of a typical suicider with CAD can be described as follows: an elderly male hospitalized for depression or alcohol-related disease. The method for suicide is likely to be violent (mostly hanging), and alcohol will not contribute to the suicide. Heavy alcohol abuse has been shown to be related to increased risk of cardiac diseases. In addition, alcohol dependence is also in general highly associated with risk of suicide $[14,15]$. Psychiatric consultation is highly recommended in clinical practice for cardiac patients with depression or alcohol-related disorders. It is well known that recognition of depression and treatment with antidepressive drugs are the most important factors in suicide prevention [16].

The strength of this study is that all the suicides committed in the geographically large area of Northern Finland during a 20-year period were included and evaluated. Thus, the series was not restricted to a certain age group, nor were the suicide data otherwise limited in any way. In addition, the source for the diagnoses attached to the hospital treatments was the Finnish Hospital Discharge Register, which has been shown to be reliable for use in scientific research [17]. Similarly, the Finnish death certificate form, the certification practices involved and the system for determining the cause of death have all been shown to possess acceptable validity for mortality research [18].

Since our data did not enable us to calculate the standardized mortality ratio for expected deaths, we used the Bayes' rule for conditional probabilities of suicide and CVDs. Other limitation of our study was that the ICD diagnoses extracted from the Finnish Hospital Discharge Register only include patients who have been admitted to hospital. This means that only severe cases of cardiovascular diseases that needed hospitalization are included. Unfortunately, there is no national register of outpatient treatments in Finland, and therefore our reference group may include some false-negative cases with respect to both cardiovascular diseases and depression. Also, the causality between cardiovascular diseases and depression could not be evaluated.

\section{References}

[1] J. C. Barefoot and M. Schroll, "Symptoms of depression, acute myocardial infarction, and total mortality in a community sample," Circulation, vol. 93, no. 11, pp. 1976-1980, 1996.

[2] R. Rugulies, "Depression as a predictor for coronary heart disease: a review and meta-analysis," American Journal of Preventive Medicine, vol. 23, no. 1, pp. 51-61, 2002.

[3] K. Van der Kooy, H. van Hout, H. Marwijk, H. Marten, C. Stehouwer, and A. Beekman, "Depression and the risk for cardiovascular diseases: systematic review and meta analysis," International Journal of Geriatric Psychiatry, vol. 22, no. 7, pp. 613-626, 2007.

[4] G. L. Sowden and J. C. Huffman, "The impact of mental illness on cardiac outcomes: a review for the cardiologist," International Journal of Cardiology, vol. 132, no. 1, pp. 30-37, 2009.

[5] F. Lespérance and N. Frasure-Smith, "Depression and heart disease," Cleveland Clinic Journal of Medicine, vol. 74, supplement 1, pp. S63-66, 2007.

[6] B. Tomenson, L. Cotter, A. Heagerty, and F. Creed, "Depression is a risk factor for mortality after myocardial infarction. Fact or artifact?" Journal of the American College of Cardiology, vol. 49, no. 18, pp. 1834-1840, 2007.

[7] R. C. Ziegelstein, "Depression after myocardial infarction," Cardiology in Review, vol. 9, no. 1, pp. 45-51, 2001.

[8] S. Artero, B. Astruc, P. Courtet, and K. Ritchie, "Lifetime history of suicide attempts and coronary artery disease in a community-dwelling elderly population," International Journal of Geriatric Psychiatry, vol. 21, no. 2, pp. 108-112, 2006.

[9] Y. Kishi, R. G. Robinson, and J. T. Kosier, "Suicidal ideation among patients with acute life-threatening physical illness: patients with stroke, traumatic brain injury, myocardial infarction, and spinal cord injury," Psychosomatics, vol. 42, no. 5, pp. 382-390, 2001.

[10] N. Frasure-Smith, F. Lespérance, and P. Julien, "Major depression is associated with lower omega-3 fatty acid levels in patients with recent acute coronary syndromes," Biological Psychiatry, vol. 55, no. 9, pp. 891-896, 2004.

[11] D. P. Wint and M. Akil, "Suicidality in the general hospitalized patient," Hospital Physician, vol. 42, pp. 13-18, 2006.

[12] http://www.thl.fi/.

[13] E. Nylev Stenager, C. Madsen, E. Stenager, and J. Boldsen, "Suicide in patients with stroke: epidemiological study," British Medical Journal, vol. 316, no. 7139, article 1206, 1998.

[14] A. Roy and M. N. Janal, "Risk factors for suicide attempts among alcohol dependent patients," Archives of Suicide Research, vol. 11, no. 2, pp. 211-217, 2007.

[15] L. Søndergård, K. Kvist, P. K. Andersen, and L. V. Kessing, "Do antidepressants prevent suicide?" International Clinical Psychopharmacology, vol. 21, no. 4, pp. 211-218, 2006.

[16] A. B. Miller, "Heart failure and depression," European Journal of Heart Failure, vol. 4, no. 4, pp. 401-402, 2002. 
[17] I. Keskimäki and S. Aro, "The accuracy of data on diagnoses, procedures and accidents in the Finnish Hospital Discharge Register," International Journal of Health Science, vol. 2, pp. 1521, 1991.

[18] R. A. Lahti and A. Penttilä, "The validity of death certificates: routine validation of death certification and its effects on mortality statistics," Forensic Science International, vol. 115, no. 1-2, pp. 15-32, 2001. 


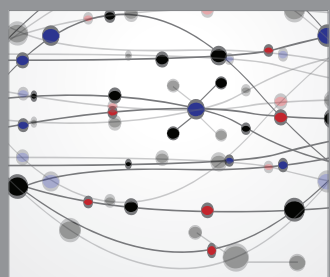

The Scientific World Journal
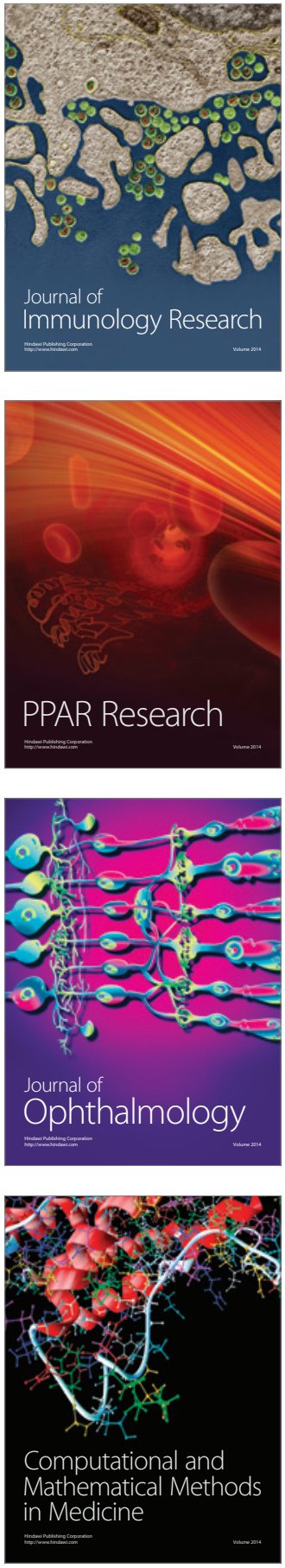

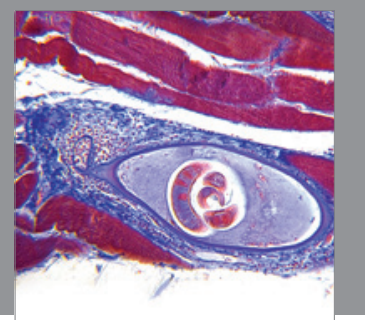

Gastroenterology

Research and Practice
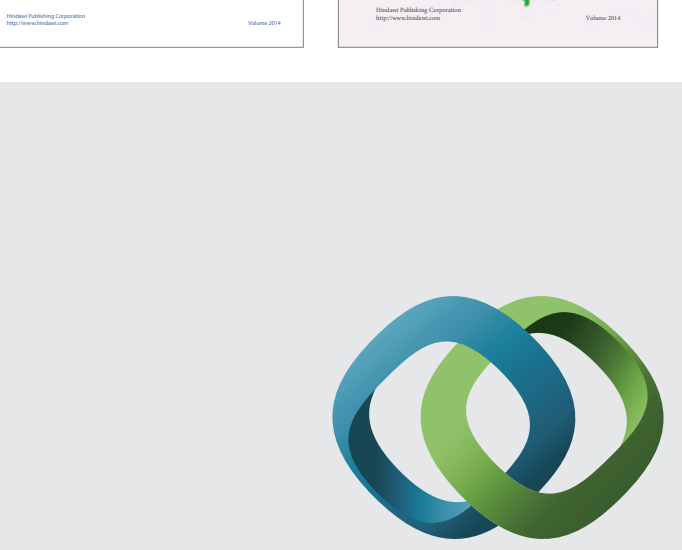

\section{Hindawi}

Submit your manuscripts at

http://www.hindawi.com
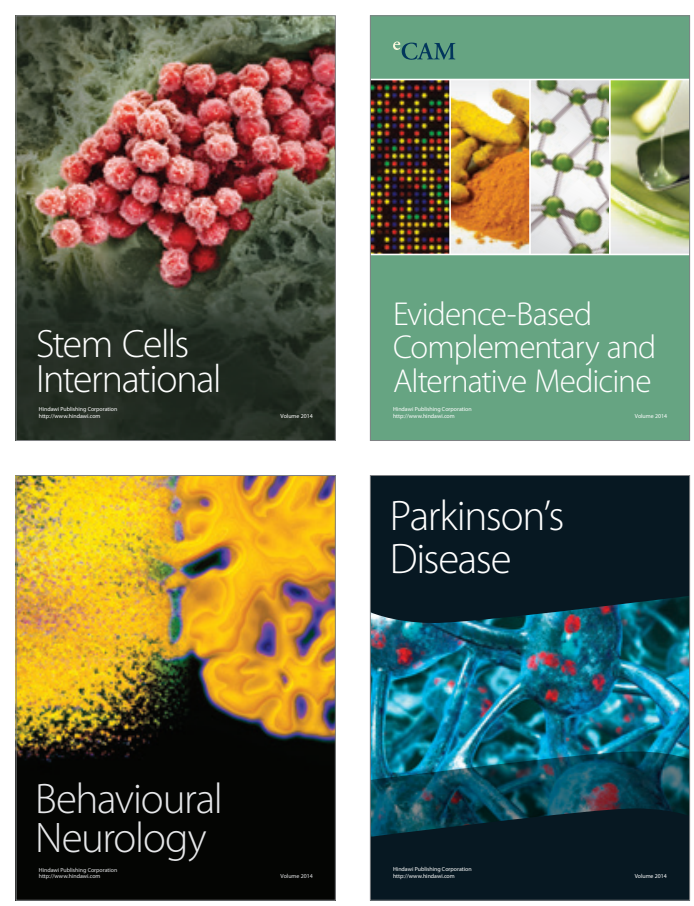

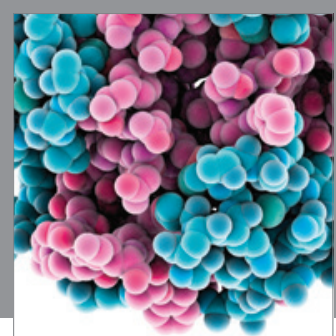

Journal of
Diabetes Research

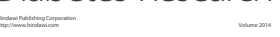

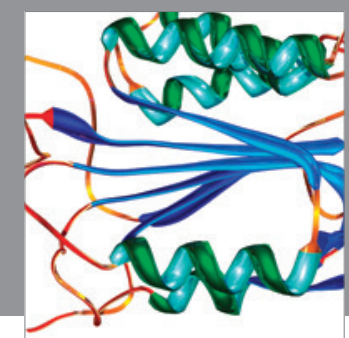

Disease Markers
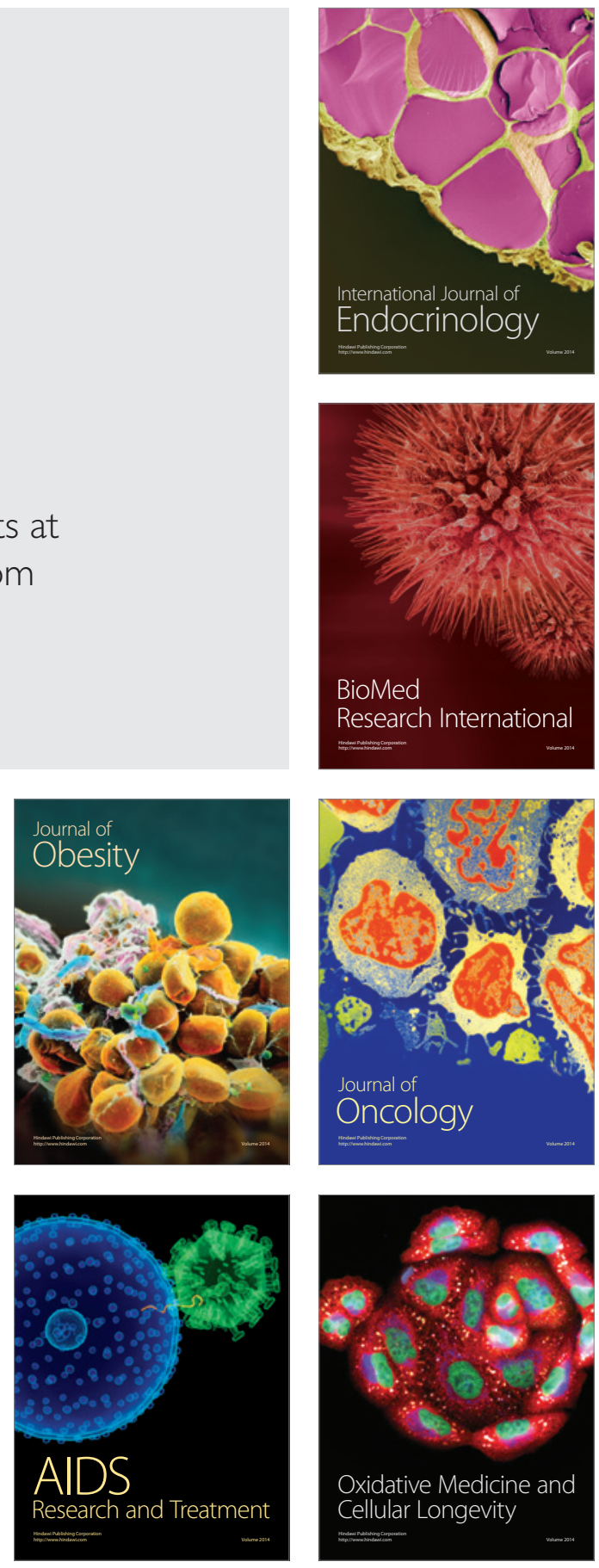